\title{
New challenges on wastewater treatment
}

\author{
Masaaki Hosomi ${ }^{1}$
}

Received: 14 February 2016/Accepted: 15 February 2016/Published online: 23 February 2016

(C) Springer-Verlag Berlin Heidelberg 2016

Challenges on wastewater treatment are diversified and differ depending not only on legislations for effluent control but also on regional characteristics and socio-economic conditions. Hence, there is a difficulty in identifying a common challenge applicable to all situations. Nevertheless, there is no doubt that implementation of a cost-effective and high-performance wastewater treatment system is of importance.

Japanese population is decreasing by more than 200,000 per year. In the society with a decreasing population, development of a sustainable sewerage system amenable to the changing situation poses an urgent challenge. To this end, the key is an energy-saving policy. In most cases, sewerage systems in Japan have been constructed in urbanized areas: three fourths of municipal wastewater in volume is treated by centralized sewage treatment systems in the whole country. The report on a new vision of sewerage wastewater management by the central government shows that annual usage of electricity for the sewage treatment systems including collection and treatment in Japan is ca. 7 billion $\mathrm{kWh}$, equivalent to the counterpart of a nuclear power plant providing power generation of about 1 million $\mathrm{kW}$. This amount of the power requirement represents $0.7 \%$ of the total electric power consumption in Japan. In sewerage utilities, basic unit of electric power consumption in Japan has been currently kept constant at $0.5 \mathrm{kWh}$ per $1 \mathrm{~m}^{3}$ of municipal wastewater. The composition of this basic unit consists of, in the descending order, $48 \%$ for wastewater treatment, $21 \%$ for sludge treatment,

Masaaki Hosomi

hosomimasaaki1130@gmail.com; hosomi@cc.tuat.ac.jp

1 Tokyo University of Agriculture and Technology, 2-24-16 Nakamachi, Koganei, Tokyo 184-8588, Japan
$14 \%$ for pumping in a wastewater treatment facility, $10 \%$ for pumping stations to collect sewage, and $7 \%$ for other minor items. Taking a look at the system configuration of wastewater treatment, a conventional activated sludge system, an advanced activated sludge system for nutrient removal, and a decentralized small-scale system (treating wastewater less than $10,000 \mathrm{~m}^{3} /$ day) require $0.23,0.30$, and $0.55 \mathrm{kWh} / \mathrm{m}^{3}$ as basic unit of electric power consumption, respectively. An advanced activated sludge system, which is mainly present in an urbanized area, e.g., in the Tokyo Metropolitan, increases energy requirement by approximately $30 \%$ in comparison with a conventional system. Notably, a decentralized wastewater treatment facility has lower energy efficiency to treat wastewater than a centralized counterpart treating large amount of wastewater.

Sewage sludge produced during wastewater treatment is excessive and needs to be appropriately treated. This wasted sludge is utilized or converted: $10 \%$ for application to agricultural lands; $13 \%$ for conversion into energy as a biogas, i.e., methane, by anaerobic digestion; $77 \%$ for disposal after dewatering and incineration followed by landfill or without any appropriate treatment. Because $80 \%$ of sewage sludge consists of organic carbon, the transformation into biogas by anaerobic digestion seems to be feasible. However, a scale of an anaerobic digestion system is not sufficiently large to be able to capitalize on merit of scale. In addition to that point, capital and maintenance costs are high. In addition, harnessing the energy content of waste sludge by anaerobic digestion is difficult. Nevertheless, current research has demonstrated that sludge in the primary sedimentation tank is suitable for methane fermentation. Furthermore, the Tokyo Metropolitan has tested the feasibility of a sludge transfer system where waste sludge is collected by pipes underground among wastewater treatment plants. This allows one to collect enough amount 
of waste sludge to the level where scale of merit for anaerobic digestion can be sufficiently applied.

In addition to energy saving in a wastewater treatment facility, of importance is emission reduction of greenhouse gases (GHG). Sewerage utilities emit 7 million tons- $\mathrm{CO}_{2} /$ year in Japan, accounting up to $0.5 \%$ of total $\mathrm{CO}_{2}$ emission. Not only $\mathrm{CO}_{2}$ but also nitrous oxide $\left(\mathrm{N}_{2} \mathrm{O}\right)$ emission warrants attention as a new target for mitigation. Although no regulatory control of GHG emission is implemented as of now, it will be established and in the future. At this point, a new framework of low carbon footprint is being incorporated into the current framework where cost effectiveness and high performance have so far been challenges in wastewater treatment. Hence, an optimum point should be investigated to allow for development of a technology where these three challenges can be concomitantly met.

Particularly, the field of biological wastewater treatment is entering a new paradigm where anaerobic ammonium oxidation (anammox), conversion of ammonium and nitrite into $\mathrm{N}_{2}$ in the absence of oxygen, becomes central for nitrogen removal from wastewater streams. This unique reaction discovered by researchers in the Netherlands in the mid 1990s is considerably advantageous in the standpoint of cost effectiveness; according to stoichiometric calculation, nitrogen removal via anammox reaction reduces oxygen demand, hydrogen donor demand, and excessive sludge production by 62,100 and $88 \%$, respectively. However, anammox reaction necessitates partial ammonium oxidation to nitrite as a preliminary step, which brings potential risk to produce substantial amount of $\mathrm{N}_{2} \mathrm{O}$. Therefore, mitigation of $\mathrm{N}_{2} \mathrm{O}$ production in a partial nitritation and anammox process is highly desirable to achieve multiple demands, i.e., improvement of cost effectiveness and reduction of GHG emission. 